International Journal of English Literature and Social Sciences
Vol-6, Issue-4; Jul-Aug, 2021
Journal Home Page Available: https://ijels.com/
Journal DOI: $10.22161 /$ ijels

Peer-Reviewed Journal

\title{
Multi-modal Dissemination of Jingzhou Poetry in the Tang Dynasty
}

\section{Zhang Liuyue ${ }^{1}$, Ma Yan ${ }^{2}$}

\author{
${ }^{1}$ School of Foreign Studies, Yangtze University, Hubei, 434023, PRC China \\ Email: Zhangliuyue98@163.com \\ ${ }^{2}$ School of Foreign Studies, Yangtze University, Hubei, 434023, PRC China \\ Email: 630110270@qq.com (correspondence)
}

Received: 18 Jul 2021; Received in revised form: 16 Aug 2021; Accepted: 21 Aug 2021; Available online: 31 Aug 2021

C2021 The Author(s). Published by Infogain Publication. This is an open access article under the CC BY license

(https://creativecommons.org/licenses/by/4.0/).

\begin{abstract}
As China gradually approaches the center of the world stage, the task of cultural communication is becoming increasingly urgent. Jingzhou poetry in the Tang Dynasty contains regional and temporal characteristics, while itsdissemination was restricted by internal and external factors. To speed up the pace of Chinese Culture Going Out, some suggestions for its dissemination were put forward based on the multi-modal theory. This paper adopts the most suitable multi-modal approach according to different themes of poetry so as to transmit the beauty of form and internal Chinese cultural values to receiving countries.
\end{abstract}

Keywords - Jinzhou poetry, the Tang Dynasty, Multi-modal, external dissemination.

\section{INTRODUCTION}

Jingzhou, also named "Jiangling" in ancient times, owns a long history and splendid culture. Since its transportation hub status, Jinzhou contains rich the Three Kingdoms Period (220 to $280 \mathrm{CE}$ )cultural relics and has created Chu Culture that is comparable to the ancient Greek Athens culture. And most poets in the Tang Dynasty enjoyed traveling around, thus Jingzhou was a reverie for them because of its profound historical and cultural background (Zhang Xingwang, 2013). Poets in the Tang Dynasty left many cultural treasures related to Jingzhou. However, due to the differences between Chinese and Western languages, thinking patterns and cultures, the dissemination of Chinese culture like Jingzhou poetry in the Tang Dynasty abroad is not promising. At present, many translations of Chinese cultural classics are only used for communications between domestic scholars but have not been popular overseas. On August 12th, 2021, after we selected < full text > item in CNKI and input "dissemination of Jingzhou poetry during the Tang Dynasty" in Chinese, the website showed 8,217 related articles. But when we added "multi-modal", the number decreased to 15 and most of them had low correlation with "multi-modal dissemination". Therefore, we believe it is necessary to explore the dissemination of Jingzhou poetry in the Tang Dynasty from a multi-modal perspective. This paper is divided into six sections. The first 
section is an introduction of the whole paper. The second section introduces the development status of Multi-modal theory in the field of Chinese classical culture. Section Three demonstrates numerous internal and external factors in the dissemination of Jingzhou poetry in the Tang Dynasty and the following section introduces multi-modal media can help us solve problems in its dissemination. The fifth section put forward some suggestions according to different themes of poetry. The last section draws a conclusion that we should complement traditional paper communication media with multi-modal media to let Chinese classical voice heard.

\section{MULTI-MODAL DEVELOPMENT STATUS IN THE FIELD OF CHINESE CLASSICAL CULTURE}

In the thirtieth group study session of the Political Bureau of the CPC Central Committee, general secretary Xi Jinping stressed improving the country's capacity for engaging in international communication to present a true, multi-dimensional and panoramic view of China. To show the "sail" of Chinese culture to the world, we have to ride the waves of the new era. Nowadays, information network media is developing rapidly. In view of the problems caused by differences in languages, thinking patterns and cultures in the external dissemination of Chinese cultural classics, we have to resort to the multi-modal audio-visual symbols in the new media era (Geng Jingbei, 2108).

Multi-modal discourse analysis began with the discussion in The Rhetoric of Images.R. Barthes (1977) proposed the interaction between visual images and language in meaning expression. The multi-modal research in China began in Social Semiotic Analysis of Multi-modal. Li Zhanzi (2003) introduced the social semiotic analysis method based on multi-modal discourse proposed by Kress and Leeuwen to Chinese academic scholars for the first time. In addition, Liu Xiaolin (2015) introduced multi-modal discourse analysis from the narrative view in Multi-modal Narrative Discourse Research. But generally speaking, the theoretical research on multi-modal discourse in China is still in its infancy (Yang Ying, 2016). We mostly apply foreign multi-modal discourse analysis methods to practical things like posters, comics, film and television works. For example, Li Ziqi, a well-known online blogger, shows Chinese food culture and records the simple and beautiful rural life through video shooting, which attracts many audiences at home and abroad. However, because of poetry's unique and complex internal and external factors, it has been left behind regarding multi-modal methods. Many classic poems are restricted by cultural differences or texts, so the status of their external dissemination seems not promising.

\section{RESTRICTIVE FACTORS IN THE EXTERNAL DISSEMINATION OF JINGZHOU POETRY IN THE TANG DYNASTY}

\subsection{External factors}

3.1.1 Attention obstacles caused by the times of poetry

Each era has its own songs that represent the times. The times needs these songs, and these songs also conform to the times. Song of Seven Sons(Wen Yiduo, 1925), March of the Volunteers(Tian Han \& Nie Er, 1935) and Singing About the Motherland(Wang $\mathrm{Zi}, 1950)$ are productions of the times. The 2020 Olympic Games was held in Tokyo recently, and the Chinese team won three gold medals on the first day, thus Chinese National Anthem March of the Volunteers resounded three times through the Olympic Stadium within one day! Chinese people are very excited each time when they sing March of the Volunteers even until now. We can see that songs with the characteristics of the times and high artistry have become the benchmark of specific times, and their popularity has not decreased over generations. However, some songs with low popularity will only be forgotten, let alone spread out. It can be seen that the spread of songs will be influenced by the public attention, so is poetry. Although Jingzhou poetry in the Tang Dynasty is full of regional and temporal characteristics, most of the people who study these poems 
are local Jingzhou scholars. Therefore, the degree of dissemination of Jingzhou poetry in the Tang Dynasty is low because scholars abroad don't pay much attention to it. 3.1.2 Dissemination barrier caused by a single medium method

Medium is also an important part of poetry dissemination. Without media, poetry is almost impossible to spread. The writer of Youth, Li Dazhao cared about his motherland so much that he was committed to writing an article to transform the pessimistic thoughts of Chinese youth and reactivate China even he was in Japan then. However, no matter how excellent this article is, it would not have such a great social impact if it had not been published in time by the media New Youth. Born in the information age, young people in the $21^{\text {st }}$ century at home and abroad were accustomed to electronic reading, thus few of them would subscribe to periodicals like New Youth. It is obvious that spreading Jingzhou poetry in the Tang Dynasty through traditional media is not enough to influence many people in the current world.

\subsection{Internal factors}

3.2.1 Translation barriers caused by special language features of poetry

Translation is absolutely important for cultural dissemination, but it is well-known that poetry translation is not a piece of cake. Poetry in ancient Chinese is famous for its brevity. Those concise words not only are a concentrated reflection of social life at that time, but also contain the poets' rich feelings and imagination. To translate the social features and poet's emotions accurately is difficult. In addition to the text, the special form of poetry also makes translators headache. Poetry is very particular about rhythm. The three aspects of rhyme, flat and deflected tones and duality, come from Chinese unique pronunciation and tones. Translating ancient Chinese poetry into foreign languages means losing some Chinese rhythmic beauty. "Dancing in shackles" means that the poet is bound by the rhythmic rules when writing poems. Of course, the translator will also be bound by the content and form of the original text.
When translators are dancing with rhythmic shackles, they may not find a balance. Such an unsightly dance is difficult to get public applause, so the dissemination of Jingzhou poetry in the Tang Dynasty is hindered in the first step.

3.2.2 Acceptance obstacles caused by aesthetic differences in poetry

Aesthetics is the main function of Chinese classical poetry. Poetry without aesthetic consciousness is undoubtedly like a boring body without soul (Geng Jingbei, 2018). Since ancient times, Chinese and Western nations have gradually created their own cultural and aesthetic systems in their respective territory. When Chinese readers see "a round moon" in a poem, they may feel homesick because it is always the time for reunion in a family, but since Western readers do not pay much attention to family, "the moon" is just a planet. They pursue romance and modernity and emphasize personal interests; thus they cannot also accept the spirit of giving up interests in their small family for the interests of their big country. Most of the poetry would not trigger their emotions similar to Chinese readers. "The spring breeze re-greens River South banks. / But when the bright moon will see me back?”（春风又绿江南岸，明月 何时照我还） will not likely to trigger their homesickness. "Since no one lives forever, / Why not leave my loyalty to the history”（人生自古谁无死, 留取丹心照汗青）may not mobilize their patriotic feelings. They even sneer at the corruption of "A steed raising red dust won the fair mistress' smiles. / How many steeds bringing her fruits died on the run!”（一骑红尘妃子笑, 无人知是荔枝来）Many classical poems with great aesthetic significance in the hearts of Chinese readers usually cannot resonate with Western readers, and it is difficult for these poems to move the audience in the receiving country.

\section{DISSEMINATION APPROACHES OF} JINGZHOU POETRY IN THE TANG DYNASTY

The form of the Tang poetry not only inherited the traditional form of Han, Wei and Yuefu folk songs, but also greatly developed the song lines style. The cultural heritage 
in this neat form of confrontation shows a kind of morphological beauty. Try to feel the morphological beauty of the Tang poetry from some fragments of Chinese famous poet Bai Juyi (772-846)'sTen Poems of Answers:

荆州又非远, 驿路半月程。汉水照天碧, 楚山插云青。 江陵橘似珠，宜城酒如饧。谁谓谴谪去，未妨游赏行。

After seeing the neat five-character poems in just two lines, especially the antithesis of the third couplet “江陵橘似珠, 宜城酒如饧”, people, as visual animals, feel refreshed. Dissemination by paper or e-books is not only portable, but also has heavy traces of information retention, which can make Jingzhou poetry in the Tang Dynasty leave a good first impression in the hearts of the audience in receiving countries. However, the language barriers caused by the differences in thinking patterns and cultures are still unable to overcome in the traditional form. Multi-modal audio-visual symbols based on information technology are very necessary then. Multi-modality refers to the combination of different symbolic modes in communication behavior and events, such as the combination of language and sound (Van leeuwen, 2005). With the rapid development of modern science and technology and the innovation of human communication methods, multi-modal discourse research has become a hot topic in interdisciplinary research (Yang Ying, 2016). Chinese ancient poetry is beautiful not only for its neat form, but for its artistic conception. The artistic conception of the Tang poetry is a psychological reflection and aesthetic experience beyond the text (Liu Xiaoming \& Wu Liqin, 2015). The common audio-visual language can directly mobilize the audiences' perceptual experience and multi-modal visual-listening thinking, which can narrow the gap of cultural differences (Geng Jingbei, 2018). In such ways, the audience can comprehensively experience the artistic conception beauty and internal value of Chinese classical poetry. Multi-modal audio-visual culture not only brings people unprecedented sensory stimulation and emotional experience, but also makes people's aesthetic trend, thinking mode and value judgment develop in a common direction subconsciously (Geng Jingbei, 2018).

\section{DISSEMINATION OF JINGZHOU POETRY IN THE TANG DYNASTY WITH DIFFERENT THEMES UNDER THE GUIDANCE OF MULTI-MODAL THEORY}

External dissemination is an activity in which a country transmits its information and establishes its image abroad so as to expand exchanges and enhance interaction (Yang Ying, 2016). Perceptual channel and symbol system are two main criteria for the division of modality. According to human perceptions, modes mainly include five kinds: vision, hearing, smell, taste and touch while according to the symbolic system involved in discourse, it mainly includes language (text), speech (sound), paralanguage, image, body movement and music (Du Jinbang, 2013). The external dissemination of Jingzhou poetry in the Tang Dynasty will be an important embodiment of Chinese culture going global. First, we should let the charm of words and form give out fully through traditional paper media, and then assist it with other senses such as hearing, sighting and so on to transmit its internal values. For poetry with different themes, we should adopt the best way to mobilize the five senses and show the artistic conception and internal cultural value of poetry to the audience of receiving countries.

5.1 Dissemination of painting poems on natural scenery under visual grammar

Kress and Van Leeuwen proposed a visual grammar for analyzing images based on Halliday's systemic functional linguistics (Kress, G. \& T.V. Leeuwen, 1996). The visual enjoyment of Jingzhou poetry in the Tang Dynasty is embodied in both its neat form and the beauty of images. Su Shi, a great Chinese poet commented on poet Wang Wei that "Reading Wang Wei's poems, I see pictures. / Appreciating his paintings, I see poems". Chinese painting poetry is a special aesthetic phenomenon in the history of world art, which combines literature and art to complement each other. Wang Wei's poem Painting is a typical example, "The hills are hued, seen from afar; / The birds are mute, 
even nearby. / The spring is gone, but the flowers remain; / The warblers seeing me won't fly". This poem seems to describe a natural scenery at a first glance, but it is actually praising a painting. The four lines of the poem constitute a complete picture of mountains, rivers, flowers and birds.

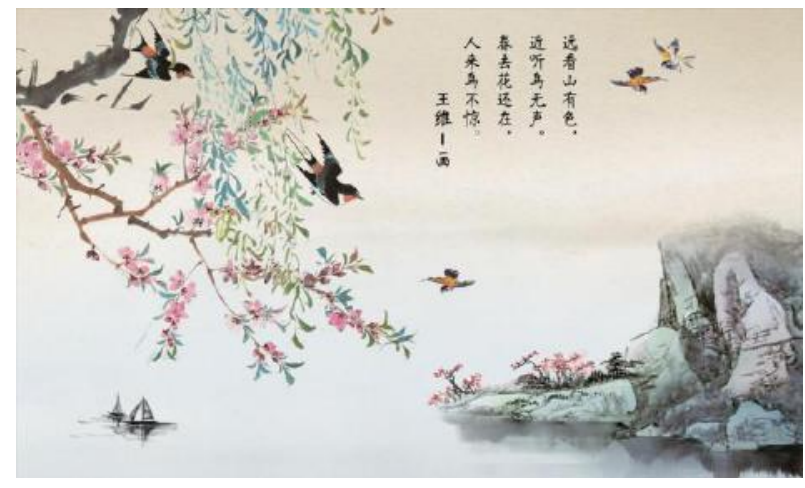

The following picture based on the poem is taken from Nicpic:

Jingzhou poetry in the Tang Dynasty which describes natural scenery has a strong sense of picture and great visual impact. We can spread this kind of poem from two aspects. On the one hand, Chinese art painters are invited to inscribe paintings on such poems, and then put these paintings as illustrations in the English version of Tang poetry books, so as to increase the interest of books and attract international readers. On the other hand, we can contact foreign art painters to draw pictures according to the translation of the poem, then compare them with the pictures of Chinese painters. Under the guideline of seeking common ground while reserving differences of those paintings, we can finally get a satisfying version. Then we display the final paintings in foreign Chinese restaurants or Chinatown and other places with Chinese characteristics abroad. In this way, we can not only attract researchers who are interested in Chinese culture but also attract the attention of the general public, which can make Jingzhou poetry in the Tang Dynasty have a subtle influence in receiving countries.

5.2 Dissemination of rhythmic poems under auditory modality

There are many poems with a strong sense of rhythm in ancient Chinese poetry. Adapting them into pop songs is the most appropriate way to spread out. CCTV channel has a large-scale poetry, culture and music program called Classics Chanting and Spreading, which is original in the mode of "harmony with poetry and song". It displays classic poetry and literary works in the way of pop music to inherit and disseminate excellent Chinese traditional culture, which won the applause of the public. The article of Youth written by Li Dazhao, mentioned before, appeared in this program once, which was sung by four CCTV hosts named Kang Hui, Sa Beining, Zhu Guangquan and Nëghmet. It made the patriotic enthusiasm of Li Dazhao's era and the positive ambition of Chinese youth closer to us in the modern world! "Music is a language without borders". God created the Babel Tower to stop human being from communicating. However, people's physiological structure is very similar; thus their feelings to a same melody are almost the same. The communication barrier in music is easy to be broken. Moreover, the entertainment of music makes it easier for people to accept it. The rhythmic adaptation of Jingzhou poetry in the Tang Dynasty is very beneficial to cultural dissemination. For poetry with strong rhythm, it is suggested to retain the original text in the rhythm of Chinese, so that the receiving country can experience the beauty of original poetry in music. As for the poetry with weak rhythm in the original text, it is suggested to translate it into the receiving country's language; thus we can turn the disadvantage of rhythm into language advantage. In addition to adapting into popular songs, we can also often carry out moderately difficult and interesting Chinese classical poetry reading competitions among overseas Chinese, Confucius Institutes and foreign students in China (Geng Jingbei, 2018).

5.3 Dissemination of narrative poetry in audio-visual modality

Narrative poetry is a genre of Chinese poetry. The initial narrative poetry comes from the folk narrative poetry that contains a relatively complete story plot and character images. When it comes to the tourism holy land of Jingzhou, most people would recommend Jingzhou Fangte Oriental 
Myth that has numerous outdoor and indoor projects. The indoor viewing projects $\mathrm{Qu}$ Yuan and Chu Music are popular places where many tourists would punch in. The project of Qu Yuan demonstrates the whole life of Qu Yuan, a famous patriotic poet, with a mixed performance of projection and real actors. It can not only offer an audio-visual feast, but also arouse the audience's curiosity about Qu Yuan and their interest in Chu culture, full of great ornamental and artistic values. The narrative poetry in Jingzhou poetry in the Tang Dynasty can adopt this method. In the first place, these poetry needs to be translated into the receiving country's language. Then we can invite screenwriters and poetry researchers to conceive stories together and then make it to animation. I believe a documentary can be effective in the dissemination of Jingzhou narrative poetry in the Tang Dynasty.

\section{CONCLUSION}

The development of literary geography research has achieved fruitful research results in all aspects. As a small tile in the academic palace of regional literature and culture, the study of Jingzhou poetry in the Tang Dynasty must have its value and significance (Zhang Lizi, 2018). As China gradually approaches the center of the world stage, the task of cultural communication is becoming increasingly urgent. Although the external dissemination of Jingzhou poetry in the Tang Dynasty has been restricted by many factors such as the times, media, poetic features and the emotional differences, but the multi-modal perspective of the new era shows us a new way. In the face of poetry with different themes, we can adopt appropriate audio-visual multi-modality to transmit the form and artistic conception beauty of Jingzhou poetry to the receiving country. Since Jingzhou poetry in the Tang Dynasty has rich internal cultural values, we should be an active cultural communicator. Complemented with traditional paper communication media, multi-modal media in the new era can bring the voice of Chinese culture to the world.

\section{REFERENCES}

[1] Zhang Xingwang.(2013). Jingzhou complex of poets in the Tang Dynasty, M.A. Thesis. Jingzhou:Yangtze University. https://kns.cnki.net/KCMS/detail/detail.aspx?dbname=CM FD201401\&filename $=1013361973 . \mathrm{nh}$

[2] Geng Jingbei.(2018).A study on multimodal discourse construction of cross-cultural communication of Chinese Cultural Classics - Taking the documentary Confucius (International Edition) as an example.Journal of Xihua University(Philosophy and Social Science)(04),48-54. doi:10.19642/j.issn.1672-8505.2018.04.006.

[3] Barthes, R.(1977).Rhetoric of the image. London: Fontana, .

[4] Li Zhanzi.(2003).Social semiotic analysis of multi-modal discourse. Foreign Languages Research(05),1-8+80. doi:CNKI:SUN:NWYJ.0.2003-05-000.

[5] Yang Ying.(2016).Research on external communication and multi-modal discourse. Global Media Journal(03),93-102. doi:10.16602/j.gmj.20160029.

[6] Geng Jingbei.(2018).The dilemma and outlet of cross-cultural communication of Chinese Classical Poetry. Journal of Southwest University of Science and Technology(Philosophy and Social Science Edition)(05),54-57. doi:CNKI:SUN:MYJJ.0.2018-05-009.

[7] Van leeuwen, T.(2005).Introducing social semiotics. London: Routledge, .

[8] Liu Xiaoming\&Wu Liqin.(2015).Multimodal co construction of vivid artistic conception in English translation of Tang Poetry. Journal of Bengbu University(01),122-126+135. doi:10.13900/j.cnki.jbc.2015.01.029.

[9] Du Jinbang.(2013).Discourse analysis. Wuhan:Wuhan University Press.

[10] Kress, G. \&T.V. Leeuwen.(1996).Reading images: the grammar of visual design . London: Routledge.

[11] Zhang Lizi.(2018).A study of Jingzhou poetry in the Tang Dynasty,M.A Thesis. Shaanxi:Shaanxi University of Technology.https://kns.cnki.net/KCMS/detail/detail.aspx?d bname $=$ CMFD201901\&filename $=1018173722 . \mathrm{nh}$ 